\title{
Akut Bulber Güçsüzlükle Prezente Olan Guillian-Barre Sendromu Olgusu
}

\author{
Case of Guillian-Barre Syndrome Presenting with Acute Bulbar Palsy
}

Nilüfer Erdoğmuş İnce, M.Fevzi Öztekin

S.B. Ankara Dışkapı Yıldırım Beyazıt Eğitim ve Araştırma Hastanesi, 1.Nöroloji Kliniği, Ankara, Türkiye

\section{ÖZET}

Guillain-Barre sendromu (GBS) akut başlangıçlı, asendan ekstremite güçsüzlüğü ve arefleksi ile karakterizedir. GBS'nun birçok nadir görülen varyantı tanımlanmıştır. Faringoservikobrakiyal (FSB) varyant bunlardan biri olup, orofarinks, boyun ve üst ekstremite kaslarında güçsüzlük ile gider. Miller Fisher sendromu (MFS) ise ataksi, arefleksi ve eksternal oftalmoparezi ile seyreden bir diğer subtipidir. Olgumuz bulber kas güçsüzlüğü ve hafif pitoz ile prezente olmuştu. Nörolojik muayenesinde faringeal ve palatal kaslarda zafiyet ve jeneralize bir arefleksi tespit edilmiş olup, ekstremite güçsüzlüğü, oftalmoparezi veya ataksi saptanmamıştı. Lomber ponksiyonda BOS proteini yüksek bulundu. EMG'sinde demyelinizan özellik gösteren yaygın sensorimotor periferik nöropati saptandı. Hasta intravenöz immunglobulin (IVIg) tedavisi sonrasında tamamen normale döndü. Akut gelişen izole bulber paralizi olgularında, sık görülen nörolojik tablolar yanında nadiren de olsa GBS varyantlarının olabileceği akla gelmeli, bu hastalıklar ayırıcı tanılarımız arasında yer almalıdır.

Anahtar Sözcükler: Guillain-Barre sendromu, faringoservikobrakiyal varyant, bulber güçsüzlük, IVIg, demyelinizan polinöropati

Geliş Tarihi: 10.12.2012
Kabul Tarihi: 14.06.2013

\begin{abstract}
Guillain-Barre syndrome (GBS) is characterized by an acute onset of limb weakness and areflexia. There are a few rare variants that have been described and one of them is the pharyngeal-cervical-brachial (PCB) variant. This variant is presenting with oropharynx, neck and proximal upper limb muscles weakness. Another variant Miller-Fisher syndrome (MFS) is presenting with ataxia, areflexia and external ophthalmoplegia. In this patient, the presentation was bulbar involvement and mild ptosis. Neurological examination showed generalized areflexia and there were pharyngeal and palatal muscles weakness. There was no limb weakness, ophthalmoparesis or ataxia. Cerebrospinal fluid examination showed raised protein level. EMG showed demyelinating sensorymotor polyneuropathy. The patient fully recovered after intravenous immunoglobulin (IVIg) treatment. The isolated acute bulbar paralysis cases should be considered as rare variants of GBS, in addition to common neurological statements and this disease should be included in the differential diagnosis.
\end{abstract}

Key Words: Guillain-Barre Syndrome, pharingeal-cervical-brachial variant, bulbar palsy, IVIg, demyelinating polyneuropathy

Received: 12.10 .2013

Accepted: 06.14.2013

\section{Giriş}

Guillain Barre Sendromu (GBS) akut başlangıçlı, asendan ekstremite güçsüzlüğü ve arefleksi ile karakterize bir hastalıktır (1). En sık görülen formu, akut inflamatuvar demyelinizan poliradikülonöropati (AIDP)'dir (2). GBS'nun birçok nadir görülen varyantı tanımlanmıştır. Faringoservikobrakiyal (FSB) varyant bunlardan biri olup, orofarinks, boyun ve üst ekstremite kaslarında güçsüzlük ile gider (3). Miller Fisher Sendromu (MFS) ise daha iyi bilinen, ataksi, arefleksi ve eksternal oftalmoparezi ile seyreden diğer subtipidir (4). MFS'da bunların dışında pitoz, orofaringeal ve yüz kaslarında güçsüzlük de görülebilir. Tanıda, beyin-omurilik sıvısı (BOS) proteininde yükseklik ve sinir iletim çalışmalarında demyelinizanizasyonu destekleyen bulgular önemlidir (1,2). Tedavisinde ise, immun mekanizmalarla oluşan bir hastalık olması sebebiyle plazmaferez veya intravenöz immunglobulin (IVIg) yarar sağlamaktadır (5).

\section{OLGU SUNUMU}

Otuz yaşında erkek hastanın öyküsünden hastaneye başvurusundan bir gün önce ayaklarında uyuşma ve karıncalanma şikâyeti meydana geldiğini, saatler içersinde bu şikâyetlerin üst ekstremitelere de yayıldığını, bir gün sonra da genizden konuştuğunu ve sıvı gıdaları yutarken genzine kaçırdığını fark ettiği öğrenildi. Bu şikâyetlerle nöroloji polikliniğine başvuran hastada serebrovasküler olay düşünülerek kranial $M R$ ve difüzyon MR istendi. Bu tetkikleri normal olarak değerlendirilen hasta, Myastenia Gravis (MG) ön tanısı ile servise yatırıldı.

Hastanın özgeçmişinde bir hafta önce geçirdiği bir üst solunum yolu enfeksiyonu dışında özellik saptanmadı. Gelişindeki nörolojik muayenesinde nazone konuşma, öğürme refleksinde azalma, bilateral göz kapağında hafif pitoz ve derin tendon reflekslerinde kayıp tespit edildi. MG ön tanısı ile servise yatırılan hastaya prostigmin (neostigmin bromid) testi yapıldı. Pitozunda ve konuşmasında herhangi bir düzelme olmadı.

Yazışma Adresi / Address for Correspondence: Nilüfer Erdoğmuş İnce, SB Ankara Dışkapı Yıldırım Beyazıt Eğitim ve Araştırma Hastanesi, 1.Nöroloji Kliniği,

Ankara, Türkiye

Telefon: 03125962840 E-posta: nilince@gmail.com

(C) Telif Hakkı 2013 Gazi Üniversitesi Tıp Fakültesi - Makale metnine http://medicaljournal.gazi.edu.tr/ web adresinden ulaşılabilir.

CCopyright 2013 by Gazi University Medical Faculty - Available on-line at web site http://medicaljournal.gazi.edu.tr/

doi: http://dx.doi.org/10.12996/gmj.2013.17 
Geniş rutin tetkikleri normal bulunan hastanın, asetil kolin reseptör antikorları negatif olarak sonuçlandı. Ardısıra sinir uyarımı testi yapıldı ve sonucu normal elde edildi. Bunun üzerine hastaya sinir iletim çalışmaları yapıldı. Çalışma sırasında ekstremite ISıSı $32{ }^{\circ} \mathrm{C}$ de tutuldu. Sinir iletim çalışmasında bilateral median, ulnar ve peroneal sinirler ile sağ posterior tibial sinir distal motor latansı (dL), motor iletim hızları (MCV), birleşik kas aksiyon potansiyelleri (BKAP) amplitüdleri ve F dalga latansları (F) bakıldı. Ayrıca bilateral median sinir 2.parmak-bilek, ulnar sinir 5.parmak-bilek ve sural sinir duyusal iletim hızları ve duyusal sinir aksiyon potansiyeli (DSAP) amplitüdleri çalışıldı. Duyu iletim çalışmasında hız tepe latansı alınarak, amplitüd ise tepeden tepeye ölçülerek hesaplandı. Motor iletim çalışmasında bilateral peroneal ve sağ tibial sinir distal latanslarında belirgin uzama, bilateral ulnar, peroneal ve sağ tibial sinir BKAP amplitüdlerinde küçülme tespit edildi (Resim 1, 2). Ayrıca tüm $F$ yanıtlarında kayıp belirlendi. Duyu iletim çalışmasında ise üst ekstremitede DSAP elde edilemedi. Bilateral sural sinir ise korunmuş idi (Resim 3). Elektrofizyolojik bulguların özeti Tablo 1 ve 2 de yer almaktadır.

Hastaya sinir iletim çalışmaları ardından yapılan BOS incelemesinde BOS proteini $58 \mathrm{mg} / \mathrm{ml}$ (15-45 mg/ml) saptandı. Hastadan gangliozid paneli istendi. Serum anti GM1, anti GQ1b, anti GD1a, anti GD1b, anti GT1a, anti GT1b negatif saptandı. Hastada BOS ve elektrofizyolojik bulgularla GBS düşünülerek 5 gün $2 \mathrm{~g} / \mathrm{kg}$ total doz olacak şekilde IVIg tedavisi verildi. Tedavi bitiminde hastanın nazone konuşması, pitozu ve yutma güçlüğü hızla düzeldi.

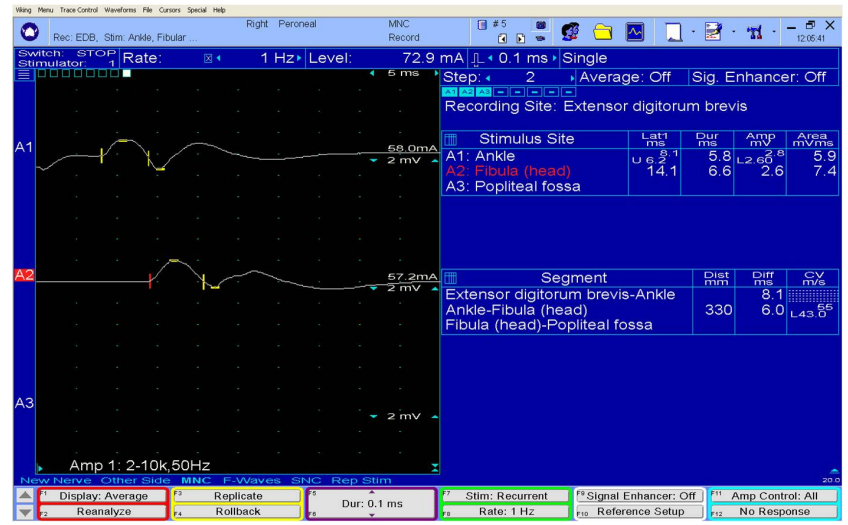

Resim 1. Sağ peroneal sinir motor iletim çalışması (0.gün)

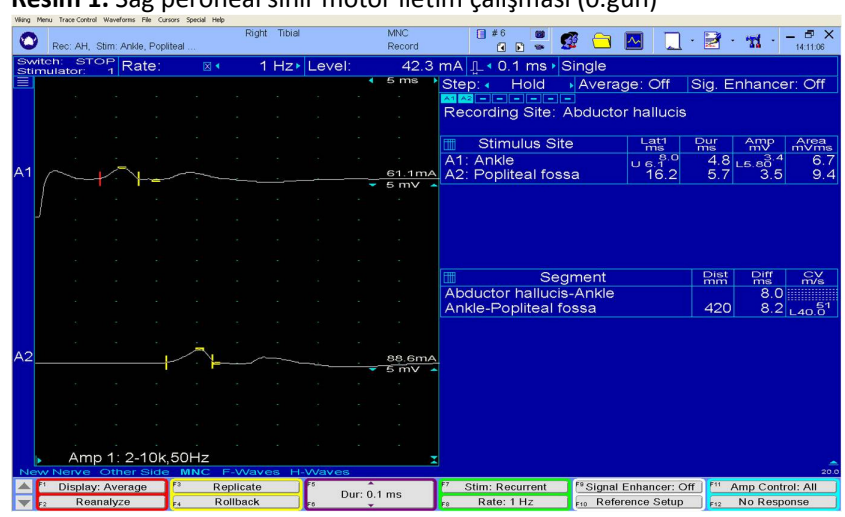

Resim 2. Sağ posterior tibial sinir motor iletim çalışması (0.gün)

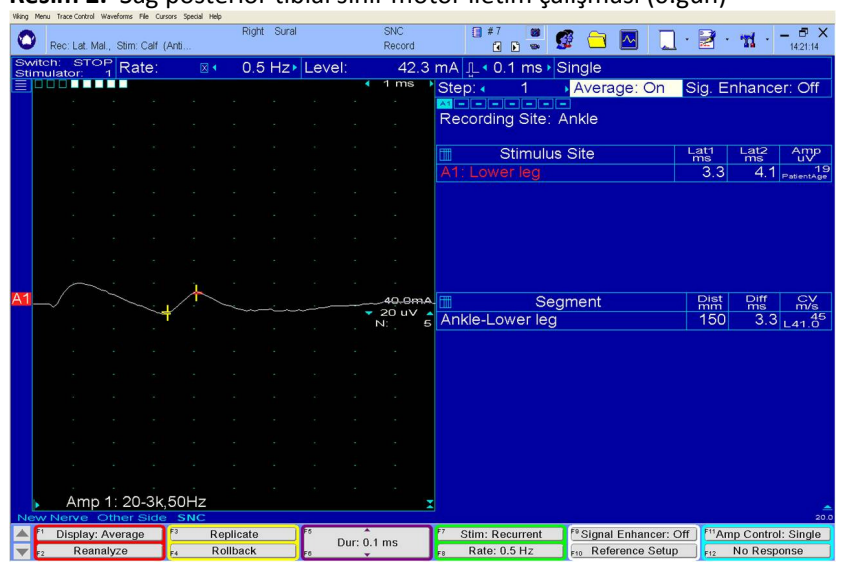

Resim 3. Sağ sural sinir duyu iletim çalışması (0.gün)
Tablo 1. Motor iletim çalışması.

\begin{tabular}{|c|c|c|c|}
\hline & $\begin{array}{l}\mathrm{DL}(\mathrm{msn}) / \mathrm{MiH}(\mathrm{m} / \mathrm{sn} \\
\text { )/BKAP } \\
\text { amp(mV)/F(msn) } \\
\text { 0.gün (geliş) }\end{array}$ & $\begin{array}{l}\mathrm{DL}(\mathrm{msn}) / \mathrm{MiH}(\mathrm{m} / \mathrm{sn} \\
\text { )/BKAP } \\
\text { amp(mV)/F(msn) } \\
\text { 14.gün (IVIg } \\
\text { sonrası) }\end{array}$ & Normal değer \\
\hline Sağ median sinir & $3,4 / 59,0 / 10,6 /-$ & $3,1 / 60,0 / 6,6 / 28,0$ & $3,8 / 49,7 / 4,3 / 32,0$ \\
\hline Sol median sinir & $3,2 / 56,0 / 14,5 /-$ & & \\
\hline Sağ ulnar sinir & $2,8 / 52,0 / 6,0 /-$ & $2,5 / 60,0 / 5,8 / 26,0$ & $3,3 / 49,9 / 7,0 / 32,0$ \\
\hline Sol ulnar sinir & $3,4 / 58,0 / 4,2 /-$ & & \\
\hline Sağ peroneal sinir & $8,1 / 55,0 / 2,8 /-$ & $6,6 / 50,0 / 6,3 / 48,0$ & $5,8 / 40,9 / 3,6 / 52,0$ \\
\hline Sol peroneal sinir & $8,2 / 53,0 / 2,1 /-$ & & \\
\hline Sağ tibial sinir & $8,0 / 51,0 / 3,2 /-$ & $6,0 / 51,0 / 10,8 / 49,5$ & $5,8 / 39,6 / 3,6 / 52,0$ \\
\hline
\end{tabular}

\section{TARTIŞMA}

Bulber güçsüzlük birçok nörolojik hastalıkta karşımıza çıkabilmektedir. Özellikle beyin sapının etkilendiği olaylarda bulber güçsüzlük görülebilmektedir. Bizim hastamızda da öncelikle beyin sapının etkilendiği serebrovasküler olay akla gelmiş ve buna yönelik difüzyon MR ve kraniyal MR istenmiş ve sonucu normal olarak değerlendirilmiştir.

Tablo 2. Duyu iletim çalışması

\begin{tabular}{|c|c|c|c|}
\hline & $\begin{array}{c}\text { DiH(m/sn)/DSAP } \\
\text { amp( } \mu \mathrm{V}) \\
\text { 0.gün (geliş) }\end{array}$ & $\begin{array}{c}\mathrm{DiH}(\mathrm{m} / \mathrm{sn}) / \mathrm{DSAP} \\
\text { amp( } \mu \mathrm{V}) \\
\text { 14.gün (IVlg } \\
\text { sonrası) } \\
\end{array}$ & $\begin{array}{c}\text { Normal } \\
\text { değer }\end{array}$ \\
\hline $\begin{array}{l}\text { Sağ } \\
\text { median } \\
2 \mathrm{P}-\mathrm{B}\end{array}$ & $-1-$ & $55.0 / 27.0$ & $39.4 / 10.0$ \\
\hline $\begin{array}{l}\text { Sol median } \\
2 \mathrm{P}-\mathrm{B}\end{array}$ & $-/-$ & & \\
\hline $\begin{array}{l}\text { Sağ ulnar } \\
5 P-B\end{array}$ & $-/-$ & $45.0 / 12.0$ & $37.3 / 7.0$ \\
\hline $\begin{array}{l}\text { Sol ulnar } \\
5 P-B\end{array}$ & $-/-$ & & \\
\hline Sağ sural & $45 / 19$ & $48.0 / 22.0$ & $33.8 / 5.0$ \\
\hline Sol sural & $43 / 14$ & $46.0 / 18.0$ & \\
\hline
\end{tabular}

Hastada bulber güçsüzlüğün yanı sıra, hafif pitozun da olması sebebiyle Myastenia Gravis de ön tanılar arasında yer almıştır. Ancak prostigmin (neostigmin bromid) testinin negatif bulunması, asetil kolin reseptör antikorlarının ve ardısıra sinir iletim çalışmasının normal olması üzerine bu tanıdan uzaklaşılmıştır.

GBS'nun nadir bir varyantı olan faringoservikobrakiyal (FSB) varyant ilk olarak 1986 yılında Roper ve arkadaşları tarafından tanımlanmıştır (6) Hastalık alt ekstremitelerde güç kaybına sebep olmadan, orofarinks, boyun ve üst ekstremite kaslarında güçsüzlük ile sınırlı kaldığı için faringoservikobrakiyal varyant adı verilmiştir. Biz olgumuzda bulber güçsüzlük, hafif pitoz ve arefleksi bulguları mevcuttur. Bulber güçsüzlüğün yanında fasiyal güçsüzlüğün, boyun ve üst ekstremitede güç kaybının olmaması sebebiyle FSB varyanta, ataksi ve eksternal oftalmoplejinin olmaması sebebiyle de klasik MFS'a tam uymamaktadır. Ancak literatürdeki benzer olgular FSB varyant olarak kabul edilmiştir $(7,8)$.

GBS'nun immun mekanizmalarla oluşan bir hastalık olması sebebiyle serumda antigangliosid antikorlara rastlanması nadir bir durum değildir. Özellikle Campylobacter jejuni ile ilişkilendirilen GBS unda anti GM1 ve anti GD1b antikorları ile anlamlı bir ilişki saptanmıştır. MFS'da ise anti GQ1b antikorları yüksek bulunmuştur. FSB varyant düşünülen bir olguda da serumda anti GT1a antikorunun saptandığı bir bildiri mevcuttur (7). Bu olgu akut başlangıçı izole bulber güçsüzlük ile başvurmuş ve FSB varyant düşülmüştür. Serumda anti GT1a antikoru yüksek tespit edilmiş, ancak hastanın yapılan sinir iletim çalışmaları normal bulunmuştur. 
Diğer bir FSB varyant olgusu ise 2006 yılında Malezya'dan bildirilmiş olup, izole bulber güçsüzlük ile prezente olmuş ve yapılan sinir iletim çalışması da demyelinizan nöropatiyi destekler bulunmuştur (8). Ancak bu olguda serumda anti gangliozid antikorları bakılamamıştır.

Literatürde 2006 yılında bildirilen olguda herhangi bir tedavi verilmeden bulguların tamamen düzeldiğinden söz edilmektedir (8). Ancak bu hastada tanı konması 1 haftayı bulmuş ve hastanın kliniği, yutma güçlüğü nazogastrik tüp gerektirecek kadar ağır seyretmiştir. Bizim olgumuzda ise tanı semptomların başlamasından sonraki 3. günde konmuş olup, IVIg tedavisi hemen başlanmış ve bulguların tedaviden sonra hızla düzeldiği görülmüştür. Ayrıca elektrofizyolojik olarak, ilk yapılan sinir iletim çalışması demyelinizan nöropatiyi destekler iken (Resim 1-2), IVIg tedavisi verildikten kısa süre sonra yapılan kontrol sinir iletim çalışması distal latanslarda hafif bir uzama dışında normale yakın olarak değerlendirilmiştir (Resim 4-5). Demyelinizasyonun bu kadar kısa sürede düzelmesinin olası olmadığı düşünülürse, bu bulgunun aslında başlangıçta olan demyelinizan bulguların gerçek bir demyelinizasyon olmayıp immunolojik mekanizmalara bağlı psödodemyelinizasyon olduğu ve verilen IVIg tedavisi sonrası ortadan kalktığı şeklinde yorumlanmıştır. Bu durum, daha çok olgu örneğine ihtiyaç duymakla birlikte, benzer olgularda IVIg tedavisine erken başlamanın semptomların hafif seyretmesi ve hem klinik, hem de elektrofizyolojik düzelmenin hızlı olması açısından önemli olabileceğini düşündürmektedir.

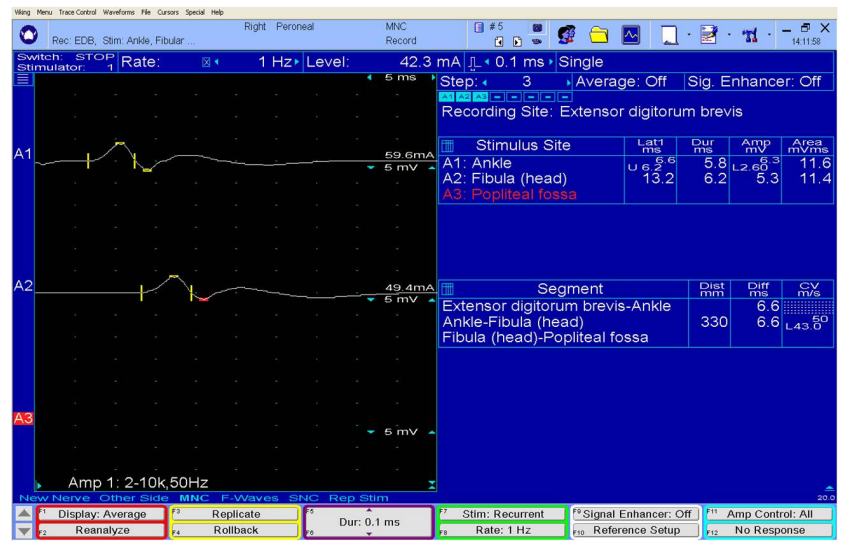

Resim 4. Sağ peroneal sinir motor iletim çalışması (14.gün)

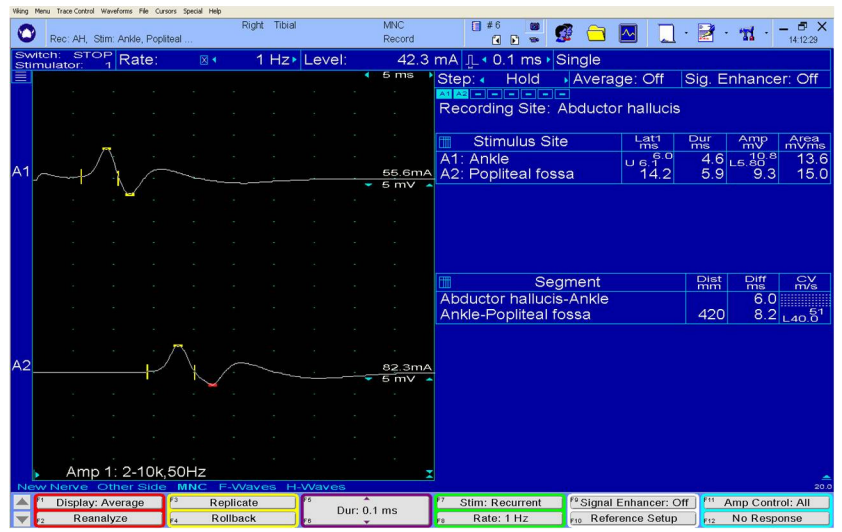

Resim 5. Sağ posterior tibial sinir motor iletim çalışması (14.gün)

\section{SONUÇ}

Sunmuş olduğumuz olgumuzdaki gibi, akut gelişen izole bulber paralizi olgularında sık görülen nörolojik tablolar yanında nadiren de olsa GBS varyantlarının olabileceği akla gelmeli, bu hastalıklar ayırıcı tanılarımız arasında yer almalıdır.

\section{Çıkar Çatışması}

Yazarlar herhangi bir çıkar çatışması bildirmemişlerdir.

\section{KAYNAKLAR}

1.Odaka M, Yuki N. Variants and differential diagnosis of Guillain-Barré syndrome. Expert Rev Neurother 2002; 2:877-9.

2.Dimachkie MM, Barohn RJ. Guillain-barré syndrome and variants. Neurol Clin 2013; 31:491-10.

3.Hergüner MO, Tepe T, Altunbaşak S, Baytok V. A rare form of GuillainBarré syndrome: pharyngeal-cervical-brachial variant. Turk J Pediatr. 2008; 50:91-3.

4.Lee KY. Anti-GQ1b-negative Miller Fisher syndrome after Campylobacter jejuni enteritis. Pediatr Neurol. 2012; 47:213-5.

5. Hughes RA, Pritchard J, Hadden RD. Pharmacological treatment other than corticosteroids, intravenous immunoglobulin and plasma exchange for Guillain-Barré syndrome. Cochrane Database Syst Rev. 2013 Feb 28;2:CD008630.

6.Ropper AB. Unusual clinical variants and signs in Guillain-Barre syndrome. Arch Neural 1986; 43: 1150-2.

7.Onodera $\mathrm{M}$, Mori $\mathrm{M}$, Koga $\mathrm{M}$, Kamitsukasa I, Fukutake $\mathrm{T}$, Hattori $\mathrm{T}$, et at. Acute isolated bulbar palsy with anti GT1a AgG antibody subsequent to Campylobacter jejuni enteritis. J Neural Sc 2002; 205: 83-4.

8.Hamidon BB. An Acute Pharyngeal-Cervical-Brachial (PCB) Variant of Guillain-Barre Syndrome Presenting with Isolated Bulbar Palsy. Med J Malaysia 2006; 61:245-7. 